\title{
Membrane Localization Motif
}

National Cancer Institute

\section{Source}

National Cancer Institute. Membrane Localization Motif. NCI Thesaurus. Code C14087.

An amino acid sequence that directs a protein to become localized in or at the cell

membrane. This targeting is determined either by the presence of hydrophobic amino

acid residues or by post-translational modification that adds a hydrophobic molecule to the protein at this site. 